\title{
FOUR-TABLET DIVINATION AS TRANS-REGIONAL MEDICAL TECHNOLOGY IN SOUTHERN AFRICA ${ }^{1}$
}

\author{
BY \\ WIM VAN BINSBERGEN \\ (African Studies Centre, Leiden/Free University, Amsterdam \\ Netherlands Institute for Advanced Studies, Wassenaar)
}

\section{Introduction}

Within any cultural domain more or less demarcated in time and space, and endowed with meaning within that domain, divination might be defined as the entire set of procedures intended to acquire knowledge which is of a supernatural nature or which is otherwise not available through everyday means such as are based upon direct sensory perception (cf. Peek 1991b; Devisch 1985). In autochthonous African medical systems, divination often forms an important diagnostic procedure. While certain major forms of African divination (dreaming, trance divination) may do without a specific material apparatus, others revolve around the use (for the production of therapeutically relevant knowledge) of a material apparatus whose construction and application are more or less institutionalised and professionalised. The latter forms of divination constitute an important field of medical technology.

In addition to the clinic offering cosmopolitan medicine, the diviner represents the main form of first-line health care with which the Southern African patient comes into contact. In most cases the diviner is also the one who offers the therapy, differing in details according to the medico-religious sub-system in which the diviner has specialised; three major sub-systems are pragmatic herbalism, sangoma-hood (involving dancing, drumming and trance in praise of the diviner's ancestors), and Independent Christian churches. For a first, exploratory divination session one usually pays a sum in the order of magnitude of whatever one can earn in a day as an unskilled labourer in the formal sector. The occasion for such a session includes not only obviously medical situations which are also recognised as such in cosmopolitan medicine, but may also involve

(C) E.J. Brill, Leiden, 1995

Journal of Religion in Africa XXV, 2 
the client's quest for power and success, or the desire to seek redress from powerlessness and adversity, in any sector of life.

The present paper will take as its point of departure a system of divination revolving around four tablets, to which I was introduced during field-work in Francistown in North East Botswana since 1988 (cf van Binsbergen 1991). My aim here is not so much ethnographic but systematic and interpretative. ${ }^{2}$ I shall first bring out the main analytical characteristics of the Francistown system: since it is a combination of a random generator and an interpretative catalogue, I discuss its mathematical properties as well as the high degree of standardisation, the classificatory vagaries, and the selective societal referents of its interpretative catalogue. The four-tablet system emerged in the middle of the second millennium $\mathrm{AD}$ in the highlands of Zimbabwe from the interaction between pre-existing local divination systems and Arabian geomancy (van Binsbergen, forthcoming and in press); after a slow subsequent spread over a limited part of the Southern African subcontinent, the twentieth century saw the rapid spread of the system over the entire sub-continent, where it is now the hallmark of non-cosmopolitan practioners. My argument seeks to explain this remarkable success of the four-tablet system by reference to the analytical characteristics exemplified in the Francistown system.

\section{The Four-Tablet System in the Francistown Area}

\section{A Divination System Consisting of a Random Generator and an Interpretative Catalogue}

In Francistown and immediately surrounding areas almost all medico-religious specialists use a set of four differently marked oracular tablets: more or less flat objects, rectangular or triangular when viewed from above, whose largest dimension is usually less than $10 \mathrm{~cm}$ (4'), and made from wood, bone or ivory. The sets differ in detail and I shall describe one set which a senior diviner gave to me, her student, in 1989. The upper side of all four tablets is indicated by a zigzag border. Out of the four tablets, two are indentured at the bottom: one with one notch, the other with two. The two non-indentured tablets have simple drawings (a house, an axe) scratched into their top surface. Thus all four tablets are clearly distinguished from each other. Moreover they carry a 
distinct name, and properties are attributed to them which distinguish them in terms of gender and seniority, as indicated in diagram 1.

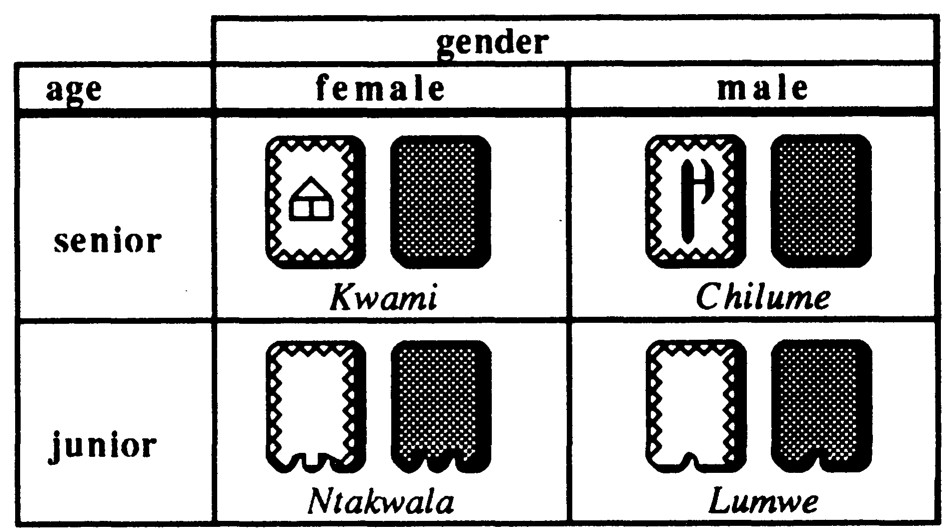

Diagram 1. An oracular set from Francistown (shaded tablets upside down)

Nowhere in the Francistown area itself could I obtain a systematic explanation of the meaning of the names of the tablets, and of their iconographical properties (i.e. the formal principles which systematically determine their symbolic representation).

The tablets are cast, and, depending on which of the four tablets fall with the marked side up or down, there are a number of different configurations possible. Each configuration has its own name, a standard praise, and a fairly definite interpretation.

It is of importance to consider the mathematical properties of the divinatory apparatus. The branch of mathematics known as combinatorial gives us the general formula: $\mathrm{C}=\mathrm{n}^{\mathrm{k}}$, where $\mathrm{C}=$ total number of different configurations (or ordered sub-sets), $\mathrm{n}=$ number of different values that each element can assume (provided each tablet can assume an equal number of different values), and $\mathrm{k}=$ number of unequivocally distinguished elements, in this case tablets (cf. Lipschutz 1983: 154f). If there are four differently marked and/or named tablets, which can each assume the two values 'open' or 'closed', then: $\mathrm{C}=2^{4}=16$. Each of these sixteen configurations has been recognised by name in the indigenous system, and has its own interpretation. From a strictly formal point of view, the physical form of the four-tablet system is nothing but an apparatus which (in a manner determined by blind chance) 
generates sixteen different values which subsequently are interpreted in the light of a catalogue of meanings. In this case the chance factor is provided by letting the tablets fall freely from both hands, which are cupped together so as to form a basin in which the tablets are tossed and shuffled. For the first throw one may simply let the tablets drop all in one go from the bag in which they are being kept.

The mathematically relevant formal aspects of the four-tablet oracle are further elucidated when we compare it with another type of oracle which is widely distributed in Southern Africa: that of semi-spherical nutshells, which when blindly cast may also fall in open or closed position. ${ }^{3}$ If we take six unmarked nutshells, as is usual in the region, there will be not sixteen but only seven different configurations possible (for now the formula obtains: $\mathrm{C}=\mathrm{k}+1$ ), and these configurations will occur with different probabilities, the probabilities associated with the most and the least frequent falls differing by a factor twenty. The determining circumstance is here that the unmarked (or, in mathematical terms, unordered) nutshells cannot be distinguished from one another. A fall in which the first nutshell is closed and all others open, looks just like one in which the first nutshell is open, the second one closed, the remaining ones open again; the associated probabilities of falls resulting in the same configuration therefore have to be added. Without ordering, far fewer configurations can be distinguished, and not all configurations have the same probability of occurrence. To produce sixteen different configurations with unmarked nutshells, we would have to use not four but as many as fifteen nutshells; this characterises the nutshell oracle as inefficient and unsophisticated.

Naming is one obvious method of distinguishing the elements in a set, or in other words of ordering them; clearly, this method has been followed in the Southern African four-tablet system. Alternatively, one might draw the detached elements one by one (instead of all in one go) from the closed bag, in this way visibly distinguishing the first-drawn elements from the second, etc. (cf. Bascom 1969: 10). Or one could literally order the elements by placing them in a fixed position, for instance by piercing them and threading them on a string.

From a formal mathematical point of view the concrete physical form of the four-tablet oracular apparatus, the connotations of gender and age, and the specific meaning and etymology of the 
names of the distinct elements of the oracular apparatus, are absolutely arbitrary, as long as they provide the ordering principle on the basis of which sixteen different configurations can be generated, each with the same associated probability. It is an essential characteristic of the Southern African four-tablet system ${ }^{4}$ that these conditions have been met.

What is moreover striking is that all mathematically possible, different ordered subsets have been actually utilised within the local divinatory system, in the sense that for each of the sixteen configurations there is a distinct name and interpretation available (cf. below, table 2). For Southern Africa, Junod (1927: ii, 603f) was the first to point this out and express his amazement about the implied mathematical insight.

The same impeccable practical application of combinatorial mathematics is found in the (largely illiterate) West African ${ }^{5}$ divination systems including the famous Ifa oracle, in the semiliterate Sikidy divination system of Madagascar which in a closely related form also occurs in the Comoro Islands, ${ }^{6}$ in classical Arabian systems from which-as all authorities agree-the West African ones and those of the Indian Ocean are derived, ${ }^{7}$ as well as in Greek, Roman, Assyrian, Tibetan and Chinese systems comprising more or less elaborate manuals including the well-known $I$ Ching. ${ }^{8}$ All these systems consist of the combination of an interpretative catalogue with a simple combinatorial random generator: the elimination of palm kernels, cowry shells, grains of wheat, dimples or lines drawn in sand, pebbles, or yarrow stalks, for among a larger assembly of identical elements, in such a way that only either one or two remain - by virtue of which the ensemble as a whole can be scored as either 'even' or 'uneven'; or the casting of two-valued tablets; or (as in West Africa) the casting of divination chains consisting of eight shells or nutshells which are each two-valued (in other words, which because of their flexible attachment to the chain can each, and independently from the others, fall in open or closed position), and which then because of their alignment along the string are automatically ordered; or by casting six- or four-faced dice-for which in Southern Africa cattle hoofs or astragali typically serve. 
Standardisation and Individual Improvisation in Tablet Divination

The divinatory system I describe displays a considerable degree of convergence between practitioners in Francistown and immediately surrounding rural areas, even if these practitioners subscribe to different socio-medical systems. These days, sangomas use tablet divination in addition to trance divination. The latter form of divination prevailed of old among Southern African spirit mediums, especially those of Nguni stock-including Zulu and Ndebele (cf. Hammond-Tooke 1981: 103f; Lee 1969). Contacts with diviners in Francistown, in Botswana's North East District and in the adjoining parts of Zimbabwe have given me the impression that the convergence concerning the local divination system exists over a vast area. Nor is the four-tablet oracle in my research area limited to one particular ethnic group. The town and surrounding villages are ethnically and linguistically a composite of, among others, Kalanga ( = Western Shona), Ndebele, Tswana (an ethnic cluster, and a language, which locally have been represented for centuries by the Khurutshe, as well as more recently by immigrants belonging to many other Tswana groups from both Botswana and South Africa), Kwi (San, Sarwa, Bushmen), and Shona. All use, either as specialists or as clients, the divination system as described here, under such designations as hakata (Shona), akata (Kalanga), and ditaola (Tswana). The names of the configurations exist both in Kalanga and Tswana, and in the multilingual environment of Botswana today may be used alternately in both languages in the course of one session.

While some diviners may still prefer to cut their own tablets, tablets to a considerable extent have become commodities, produced according to fixed, institutionalised principles and offered for sale for more or less fixed prices, especially at the medical section of the Makokoba market in Bulawayo, where Francistown healers also tend to buy their materia medica. This trade is controlled by the Zimbabwean professional association of healers, ZINATHA (Chavunduka 1978, 1986).

Some diviners use tablets which at first sight would appear to differ considerably from the standardised market specimens. In Southern Africa we find a number of different forms of the fourtablet system, which have been discussed extensively in the literature ${ }^{9}$ and which elsewhere (van Binsbergen forthcoming and 
in prep.) I consider in comparative perspective. Diviners like to extend the standard four-tablet system with one or two peripherals that have an idiosyncratic meaning to them. Often, however, the apparatus is extended in such a way that we must regard the apparatus as the four-tablet system combined with another type of oracle: the astragali oracle, a system of ten to twenty foot bones (ankle bone, heel bone etc.) of various species, sometimes augmented by pyramidally-shaped parts of cattle hoofs; the oracle thus consists of a number of 'dice' which, contrary to the tablets, may fall on more than two sides (usually four). In Botswana and South Africa the astragali oracle constitutes a major type beside the four-tablet oracle. Similarly, the four-tablet oracle may be extended by the addition of elements from the nutshell oracle (cf. Reynolds 1963: 104).

The names designating the sixteen configurations of the fourtablet oracle in and around Francistown are highly standardised. Kalanga and Tswana names are used alternately for the sixteen configurations, but with considerable consistency; the same applies to the interpretative catalogue the practitioners have learned by heart during their apprenticeship.

The convergence of the interpretative system is enhanced by the existence of professional associations of diviners. ${ }^{10}$ One of the two main associations in the research area is the Kwame/Legwame Traditional Association of Botswana. Kwame (and its Tswana form Legwame $)^{11}$ of course refers to one of the four tablets. Expertise in the use of the divination system as described in the present argument is one of the conditions for membership. The Kwame/Legwame association has stimulated a considerable uniformity of divinatory practices over a vast geographical area.

Against this background the room for personal improvisation is far more limited than one would be inclined to think on the basis of the current, 'praxeological' studies (e.g. Werbner 1989; Devisch $1985,1991)$ of diviners as more or less unique, extremely creative Culture Heroes, unimpeded by institutionalization. The real room for improvisation and for a brilliant personal 'performance' lies in the concrete interpretations, and in general in the way in which the diviner shapes the communication process with the client in the course of the session. Here the interpretative catalogue leaves all the room which the diviner could require, by its very flexibility and tautological nature, and this as part of, rather than as deviation from, the divinatory system itself. 


\section{The Interpretative Catalogue}

In the Francistown system each of the sixteen possible configurations which the four tablets can assume after a throw are interpreted according to a number of different aspects or dimensions, which all refer to the client's situation: (a) ancestors (b) body (c) social environment (d) sorcery in that social environment (e) property (f) generations immediately above the client (g) animal species (mainly referring to clans which, across the boundaries of linguistic and ethnic groups, occur in the societies of Southern Africa). Moreover, for each of the sixteen configurations there is (h) an abstract, general aspect which is supposed to sum up the basic meaning of that configuration. The standard praise (i) which is accorded the tablets when a particular configuration appears, in most cases refers to the abstract general aspect. This also applies to the stereotypical interpretation, usually in the form of an exclamation (j), which serves as some sort of shorthand for the many, often mutually contradictory, meanings packed into the various dimensions of a configuration.

Let us for example consider the configuration 100 . Its Kalanga name simply means 'two' (Zvibili), its Tswana name: 'shoe on which to go visiting' (Sethlako sa kayeta keetetswe). The abstract meaning is 'two', but 'with the concept of movement implied' (which is dominant in the Tswana meaning). Not all dimensions of Zvibili have been completely documented. The kinship aspect is not specified, but since here we are dealing with the two male tablets the kinship implied is that of a father with his son. Nor has, to my knowledge, specific association with any animal species been clearly indicated. The other dimensions have been filled as follows:

-ancestors (if this configuration appears in the context of preparations for a sacrifice): 'the ancestors will speed to the sacrifice on both legs [eagerly]'; 'the ancestors of both father's side and mother's side will come to the sacrifice'

-body: 'two legs, two feet'; 'shifting pain'; 'the complaint may get better on returning home'

- sorcery: 'witches came to your house at night and accomplished their evil work'

-social: (concerning a journey) 'you depart, reach your destination, and return safely' 
- property (specifically lost property): 'this property cannot move by itself, so someone must have taken it away'. -praise: 'two boys or two girls'

Zvibili, arbitrarily chosen from among the sixteen, shows that the meaning of the seven dimensions is not defined along strict derivational rules from the basic meaning but by loose association which takes a different direction every time. In the 'conventionalised' (Junod 1927: ii, 608; Hammond-Tooke 1974: 104) interpretation of the configuration the various aspects are not entirely unconnected, yet they cannot be relegated to one deep structure via simple and systematic transformations. For instance, the three interpretations of Zvibili in its bodily aspect have been derived from that configuration's basic meaning in different, unrelated ways.

What is also clear from the example of the Zvibili configuration is that four constituent tablets, each with its own specific value as to gender and seniority, in the interpretation of the configuration are hardly considered in their individual properties: it is the configuration as a whole which is being interpreted, and the individual properties of Kwami, Chilume, Ntakwala and Lumwe (as attributed to the distinct tablets of that name, and to the configurations in which that particular tablet is the only one to be open, face-up) completely dissolve into that whole. Earlier studies of the four-tablet system, especially with reference to Zimbabwe, have laid strong emphasis on the individual properties of the constituent tablets, seeking to explain the meaning, and its positive or negative overtones, of a particular configuration from the systematic interplay between these individual tablet properties. For instance, since the tablet, or the single-face-up configuration of Chirume (the junior male tablet in the Shona nomenclature) is particularly associated with sorcery, the sorcery dimension of all the other configurations would also be claimed to depend on the fall, in a particular configuration, of the Chirume tablet in open or closed position (Hunt 1950; cf. Tracey 1963). Nothing of the kind occurs in the Francistown system. The conventionalised system operates on the basis of the principle: the whole is more than the sum of its parts. It takes on a high degree of abstraction and systematics in one medico-religious domain, divination, which thus more or less stands on its own and is not, or no longer, conceptually dependent on the structure of social life outside divination. It is this particular form of semi-autonomous conventionalization which, as I shall 
argue below, has been of decisive importance in the success of the four-tablet system in the modern Southern African world.

A closely related issue is that of microdramatics, which may be said to constitute the opposite of conventionalization in the interpretative catalogue.

Junod (1925, and especially 1927) published famous analyses, not only of the Pedi four-tablet oracle which among the Tsonga was at the time represented by only one diviner, but also of the nutshell oracle and especially of the astragali oracle-the latter two types prevailed among the Tsonga when Junod studied them. According to Junod's analysis, the elements when thrown (and they were always more than four) retained their individual contribution to the interpretation of the ensemble. Not only their fall to a closed or open position, but also their position according to an imaginary coordinate grid projected onto the ground, and their relative position vis-à-vis each other, determined the interpretation. The elements represented important social roles and positions in the client's social surroundings, as well as the hunter's quarry, and important aspects of the natural environment; the relative position of the elements after the throw were taken to provide information on existing tensions, conflicts and insecurities in the client's situation. Werbner has subsumed this mode of interpretation under the apt term of 'microdramatics' (1989b), which since has been adopted by others (e.g. Shaw 1991). In Werbner's analysis of a variant of the fourtablet system among the Botswana Tswapong (where both tablets and foot bones were used), he lays great stress on microdramatics as a source of the tension, catharsis and insight as built up in the course of the divination session.

In the contemporary Francistown system we encounter no microdramatics to speak of: not in the absolute and relative position of the four tablets as marked according to gender and seniority, not even in the concrete presence (face up) or absence (face down) of certain tablets endowed with specific individual properties; it is exclusively the total configuration which determines the interpretation.

Just as there is, per configuration, no fixed relationship between the basic meaning and the various interpretative aspects, there is neither any fixed rule by which we might derive, from a configuration's basic meaning, its specific meaning under any particular aspect or dimension. For instance, if we know the basic meaning 
of Zvibili, this does not help us to predict what the interpretative catalogue will list as the bodily aspect of that configuration. Space is lacking to present the data for all dimensions (a) through (j), but we can demonstrate our point by considering in detail only one dimension for all sixteen configurations. Let us for instance concentrate on the bodily aspect, which attaches specific symptoms of disease to each configuration. The data are summarised in table 1.

In all cases the derivation from basic meaning to illness aspect takes a different form again, the connection is loose and associative, and it is impossible to give general derivational rules.

The tablet oracle is essentially an open associative device, but one which to the client appears emphatically as a fully determined mechanism controlled by a supernatural causality which cannot be influenced directly by humans-the tablets' fall as determined by what Western science would call stochastic chance, and what diviners and clients would identify as the client's or the diviner's ancestors, the High God, or a demi-god ${ }^{12}$ presiding over divination. The divination apparatus is a machine for generating an unlimited number of different stories: stories at least one of which contains meaning and revelation for the client-a directly applicable poem written under specific reference to the client's life and problems. The many hours which the apprentice diviner spends on exercising with virginal dummy tablets, are not just meant to imprint the correct name and meaning - along the various dimensions-of each tablet and each configuration (although this is difficult enough in itself), but also to develop the candidate's ability to spin stories, of ever greater depth, relevance and drama, on the basis of the narrative material which the interpretative catalogue offers and which can be seen to unfold in the succession of throws.

The interpretative catalogue in all its dimensions reproduces a complex, rather complete social order-many aspects of the human life experience fit into it, from bodily complaints to sexuality, from movement in space and time to guilt and redemption from generation to generation, from conflict and rivalry to conciliatory action in the form of shared sacrificial rituals, meals and festivities. The totemic animals, signifying clans, render the scheme applicable to broad categories of people, and to the group relationships between them, in the ethnically diverse society of Southern Africa. The catalogue constitutes a cosmology. It recreates a timeless microcosm in which the client does not necessarily feel quite comfortable (for 
many Southern African clients are more orientated towards town, wage labour, formal organisations, mass consumption and electronic media than to the historic symbolic order of the home village), but which does offer the client identification and revelation. Not only is it easy to cross over, within the universe of the catalogue, from one interpretative path to another, to one which promises more insight-the alternative path does promise more insight because it is so easy to cross over from the catalogue to the client's biographical reality. So flexible are the scheme and its application, that at whichever point (triggered by whichever configuration, and by whichever specific dimension of that configuration) one enters the catalogue, one can usually arrive at an interpretation which in a recognisable form addresses the client's hopes and fears.

Some aspects of life, meanwhile, are strikingly absent from the interpretative scheme: for instance modern politics and the state, formal organisations in general, workers' experience under capitalism, peasants' and villagers' experiences under conditions of land appropriation and powerlessness. These structural themes, however central to Southern African societies of the twentieth century, the interpretative catalogue, without critique or rebellion, reduces to neutral and entirely individual anecdotal issues: travelling in the context of labour migration, getting a job, competition among work-mates. This sleight-of-hands has a therapeutic meaning, and cannot be argued away merely by reference to the fact that these social phenomena did not make part of the historic rural world-view in which the four-tablet system got established in the first place. Many clients come to the diviner with problems deriving from the 'modern' sphere; it is these problems which may cause the clients particular anxiety and bitterness, and for which particular revelation, reconciliation and hope are sought. Since these problems do not feature in the interpretative catalogue, the divination seeks to resolve them not by confrontation but by re-definition. They are relegated to the status of mere surface manifestations of conditions that are both more fundamental and more easily redressed or controlled than the modern state or the capitalist economy are. Departing from the negative modern experience the client is led back to matters which, allegedly, either spring from ancestral wrath, can be redressed by ancestral protection, or can be reduced to the relatively manageable, personified scale of sorcery and counter-sorcery. The divination process confronts the irresolvable problems 
Table 1. Symptoms of disease as associated with the sixteen configurations

\begin{tabular}{|c|c|c|c|}
\hline no./name & conirguration & $\begin{array}{l}\text { characteristic leature and } \\
\text { abstract meaning }\end{array}$ & bodily reterent \\
\hline 1. Kwami & (⿳⺈⿴囗十灬 & house, unchangeable, permanent, stone, eye & small child's body, fontanel \\
\hline 2. Chilume & & maleness, spear, axe, sorcery & $\begin{array}{l}\text { pain, blood clot, abdominal blood vessels } \\
\text { crossed }\end{array}$ \\
\hline 3. Ntakwala & & two indentures; gaudy interlaced design & $\begin{array}{l}\text { blood; small child's body; worm infestation } \\
\text { bright colours }\end{array}$ \\
\hline 4. Lumwe & & $\begin{array}{l}\text { one indenture; uvula, little tongue, speech; } \\
\text { degree of doubt or decisiveness, intention, } \\
\text { free will }\end{array}$ & throat? \\
\hline 5. Mbizimbili & & pair-wise, as in a grave; the person is dead & $\begin{array}{l}\text { kidneys; any organ of which a person has } \\
\text { got two (eyes, ears); your life is in danger }\end{array}$ \\
\hline 6, Mbango & & fence post, home, dust, things of the home & $\begin{array}{l}\text { womb, pregnancy; intestines; eating of } \\
\text { intestines (of 'inside' meat) as sign of } \\
\text { accomplished sangomahood }\end{array}$ \\
\hline 7. Take & 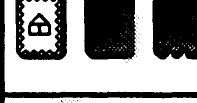 & $\begin{array}{l}\text { shoe, the client knows the problem, may have } \\
\text { hope }\end{array}$ & $\begin{array}{l}\text { the treatment will benefit you; the } \\
\text { complaint is a recurrent one }\end{array}$ \\
\hline 8. Mpululu & & $\begin{array}{l}\text { ululating, joy (wedding); mouming (funeral); } \\
\text { good morale, energy }\end{array}$ & \\
\hline
\end{tabular}




\begin{tabular}{|c|c|c|c|}
\hline 9. Zvibili & & a pair, with the concept of movement & $\begin{array}{l}\text { two legs, feet; shifting pain; may be better } \\
\text { when reaching home }\end{array}$ \\
\hline 10. Mitengwe & & women's skirts, knot, tied together & $\begin{array}{l}\text { tied kidneys; lust; tying up the } \\
\text { menstruation by magical means }\end{array}$ \\
\hline 11. Ku-lela & $\Theta$ & $\begin{array}{l}\text { overpowering; exercise of power; one side is } \\
\text { dominating the other; the problem is getting } \\
\text { worse; rule; legitimate property }\end{array}$ & $\begin{array}{l}\text { stomach, belly, waist; pregnancy; the foetus } \\
\text { is not comfortable }\end{array}$ \\
\hline 12. Vuba & & $\begin{array}{l}\text { mixture; heat; heart burning with desire; } \\
\text { determination; sacrifice; to find }\end{array}$ & $\begin{array}{l}\text { not one specific part but the entire body is } \\
\text { affected; you will be tired }\end{array}$ \\
\hline 13. Kwaga & A & receive, take; the problem is in the receiving & pregnancy; stabbing wound; poison \\
\hline 14. Ntagwana & & $\begin{array}{l}\text { father's sister, directness in terms of time and } \\
\text { place }\end{array}$ & intestines, stomach, belly \\
\hline 15. Mbunga & & $\begin{array}{l}\text { to come together, group, meeting, assembly, } \\
\text { collection }\end{array}$ & the entire body is affected \\
\hline 16. Mashangula & & $\begin{array}{l}\text { sleeping mats, there is no information, no } \\
\text { meaning; 'you are erasing the problem' }\end{array}$ & any disease ; sexually transmitted disease \\
\hline
\end{tabular}


of the modern, inimical world by declaring them irrelevant or secondary, replacing them with other problems which, in a microcosm of which both the living and the dead make part, can be resolved by divination, therapeutic action and sacrifice. ${ }^{13}$

\section{The Four-Tablet Divination as Trans-regional Medical Technology}

The Francistown system is far from standing on its own. Fourtablet divination, with similar tablets (although differing in details of marking, shape and material used), with identical or kindred names for the tablets and for the configurations which they form, with identical mathematical properties, and with interpretative catalogues which broadly converge, have been described for large parts of Southern Africa. On the basis of the extensive literature cited above it is possible to indicate on a map of the region (cf. diagram 2) (a) the geographical distribution of the system in Southern Africa in the nineteenth century (presumably going back to the invention of the system in fifteenth century Zimbabwe), as well as (b) the recent expansion of the system in the course of the twentieth century.

After a gradual expansion in the course of almost half a millennium, the four-tablet system spread over the whole of Southern Africa in the course of the twentieth century, no longer by taking root in the specific local cultures, but by becoming an almost universal attribute of the mobile and trans-cultural, professional practioners of autochthonous medicine, in rural areas but also, and particularly, ${ }^{14}$ in urban environments. It is the latter category of practioners which in the literature is often, somewhat negatively, described as 'popular' or 'modern' diviners, doctors or healers.

We see then that four-tablet divination, as a professional attribute, breaks through such boundaries (always far more porous than classic anthropology has assumed) as existed in the past between local cultures, as well as between the medico-religious subsystems that used to be defined within those local cultures. It may be that the most important single factor in the contemporary spread of the four-tablet system throughout Southern Africa has been that spirit mediums in the Nguni tradition, which of old concentrated on mental divination, have come to adopt the tablet system-for which they are often reproached by herbalists who do not practice 

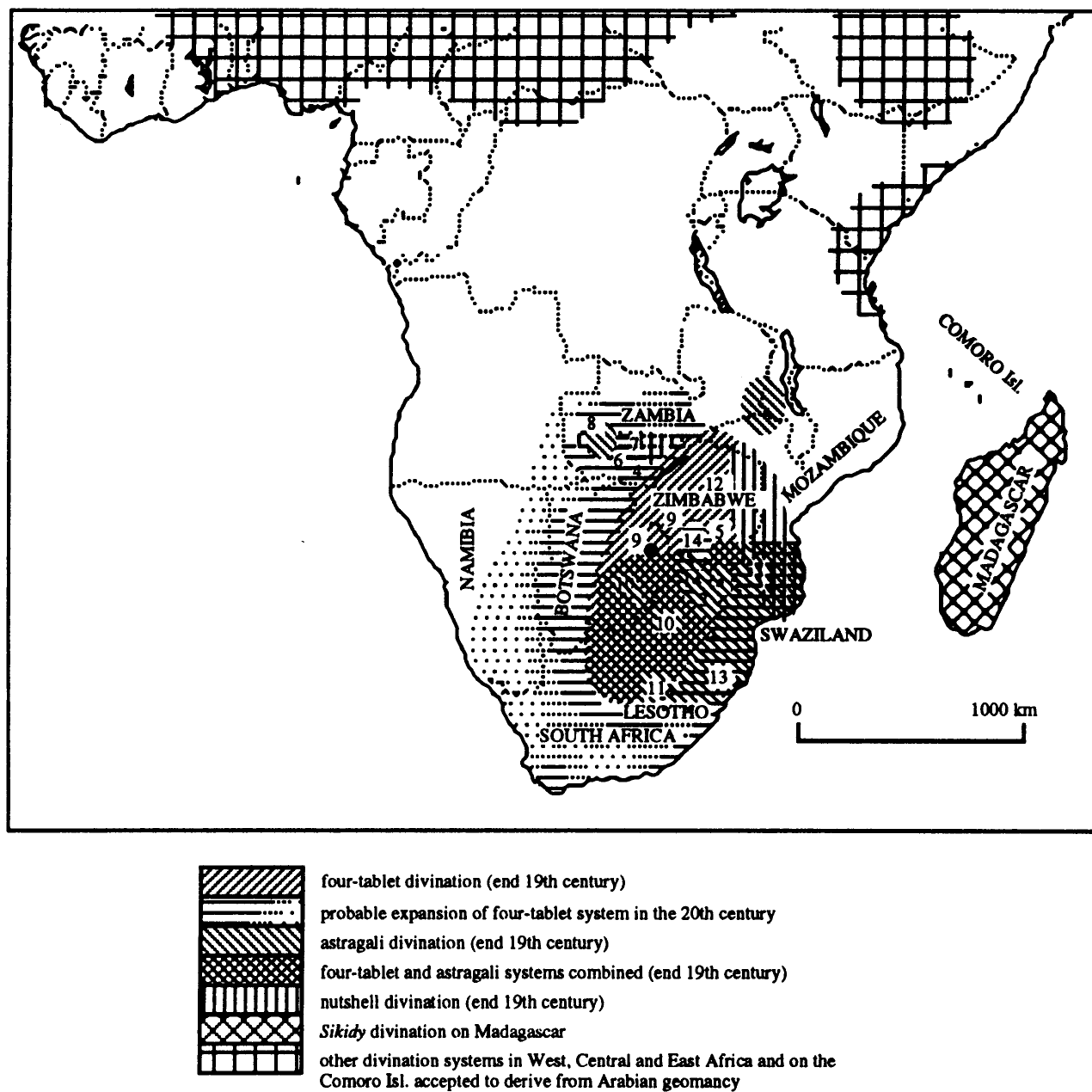

four-tablet divination (end 19th century)

probable expansion of four-tablet system in the 20th century

astragali divination (end 19th century)

four-tablet and astragali systems combined (end 19th century)

nutshell divination (end 19th century)

Sikidy divination on Madagascar

other divination systems in West, Central and East Africa and on the

Comoro Isl. accepted to derive from Arabian geomancy

- Francistown

selected ethnic groups

1. Tsonga: 2. Pedi; 3. Venda; 4. Leya; 5. Karanga; 6. Totela; 7. Ila; 8. Lozi; 9. Kalanga;

10. Tswana (Western Sotho): 11 .Southern Sotho; 12. Shona; 13. Zulu; 14. Ndebele

\section{Diagram 2. Geographical distribution of several divination systems in Southern Africa}

music and dance. Women, to whom in the past the right was denied $^{15}$ to use the four-tablet system as diviners (they were always welcome as patients) now begin to use the tablets and even play a role in their cross-cultural diffusion. ${ }^{16}$ Complex, expensive and rare divination apparatus like the Venda divining bowl and the Zambian divining basket, but also more common divination forms such as the nutshell oracle and the astragali oracle which have existed in 
the local region for a long time, begin to undergo replacement by the increasingly ubiquitous four-tablet oracle. In the process, established, bounded groups of specialist users are partly supplanted by new categories of therapists whose recruitment is far more open. ${ }^{17}$ This change of the guards goes hand in hand with an erosion of the older specialist positions since the latter concerned social functions (e.g. the prosecution of witches under local criminal law, and the underpinning of local political leadership) which the modern state has taken over, radically transformed, or suppressed. The democratisation of divination in terms of personnel is reflected in the commoditification of the apparatus: the four tablets are offered for sale as commodities in the markets. ${ }^{18}$ In this recent phase of the diffusion process microdramatics are less and less important. Likewise, the poetical praises in which the interpretative catalogue used to be enshrined disappear into the background. Instead of dramatising and personalising, the system acquires a classifying emphasisbased on a conventionalised interpretative catalogue which is less and less rooted in such symbolism of the local culture as the diviner subscribes to and is competent in. Moreover the catalogue, because of its abstraction and systematics, can be used anywhere in Southern Africa, and is applicable across the boundaries of languages, cultures, states and medico-religious sub-systems. Because of all these shifts the four-tablet oracle is likely to have acquired a relatively low prestige by comparison with other local forms of divination, ${ }^{19}$ but this is counterbalanced by the fact that it has become a central attribute of the modern non-cosmopolitan medical profession - a fact which is so clearly brought out in the name and the emblem (Kwami's ocular symbol) of one of the two Botswana professional associations. Because of the abstraction from the local symbolic context, the application of the conventionalised system in the hands of the diviner at the same time has become more difficult to check by lay clients, and this has constituted a further stepping-stone towards professionalization of African medicine.

It is important to realise that this twentieth-century expansion of the tablet oracle has taken place in the face of repression and persecution, not only by Christian missions but also by specific legislation and law enforcement on the part of Southern African governments in the colonial period..$^{20}$ This repression was based on the colonial perception that in Zimbabwe the hakata were essential 
in the selection of victims for human sacrifice in territorial cults. ${ }^{21}$ The four-tablet system has grown and spread under oppression, has had to operate underground for decades, and therefore has become a militant aspect of twentieth-century non-cosmopolitan medicine.

In this way the twentieth-century phase of the diffusion of the four-tablet system over Southern Africa reflects fundamental transformations which the society and culture of this part of the world have undergone in this century under the impact of the modern, bureaucratically organised state and of the capitalist economy. Boundary-crossing mobility of persons (from an ethnic, cultural, linguistic and geographical point of view, and especially in contexts of labour migration and urbanisation); the commoditification of many cultural forms; the fact that consciousness has come to be captured, to a considerable extent, by a complex of power and meaning which is rooted in the state and capitalism, tending towards impersonality and universalism, and transcending or denying such meaning as is constructed within the local context; such erosion of time-honoured inequalities in the local context (in terms of gender, seniority, ethnicity, ritual and political specialism) as is implied in the abstract categorization emanating from this impersonal complex-but at the same time the cultivation of new and humiliating inequalities (in terms of race, class, ruralurban contradictions and modern politics) from the centre; the emergence of new groups (including 'modern' but non-cosmopolitan doctors with their own professional organisations), whose recent association with the central state and its cosmopolitanmedical bureaucracy generates new power-this is the modern sphere within which the four-tablet system can thrive.

The interpretative system has become an impersonal catalogue, devoid of microdramatics. By comparison, the other local oracular forms increasingly appear as messy, old-fashioned, internally contradictory, and through their microdramatics rooted in a specifically local symbolic order. The four-tablet oracle, however, would be more reminiscent of the smooth, standardised, uniform industrial products which constitute the dominant material culture of contemporary Southern Africa. The commoditification aspect has now proceeded to a point of folklorisation. At least one, Whiteoperated shop in the centre of Bulawayo now offers a massproduced 'hakata package' for sale, in a neat cellophane wrapping and complete with an explanatory booklet (which is quite well 
informed and sensible at that), in which the system is advertised as a fascinating parlour game based on the time-honoured principles of African divination... At least one other version of the Southern African divination systems has already been trivialised to help fill the bookshelves of New Age esoterism, in the form of Esther Crowley's (1989) do-it-yourself divination guide: the booklet The Zulu bone oracle. Also the commoditification of the diviner-client relationship, and the combination of both democratisation and professionalisation in the diviner-client and diviner-state relationship, correspond with major themes in twentieth-century Southern African society, and in the experiences which people tend to have within that society. Therefore, I do not hesitate to explain the relative success of the four-tablet oracle by reference to this correspondence. The tablets, and the underlying interpretative catalogue, have in fact become part of the generalised, trans-ethnic contemporary culture of a large part of Southern Africa.

In our age it is clearly not just cosmopolitan medicine which creates patterns of medical action tending to uniformity over vast geographical areas. A certain degree of standardisation (of medical techniques, of materia medica, of the interpretative schemes which specialists use and of the patterns of expectation with which clients approach local medical practioners) may also occur in autochthonous medical systems, especially if these operate in a social context which has been permeated by cosmopolitan medicine. In Southern Africa we deal less and less with historical medical forms which are rooted deeply in any particular local, clearly demarcated cultural tradition. Autochthonous, non-cosmopolitan medicine in Southern Africa today consists primarily of the innovative transformations and permutations of 'traditional', i.e. historic material (symbols, ideas, techniques and material objects); in the process we witness a constant oscillation between convergence on the one hand (a case in point is the general spread of the four-tablet oracle as the trademark of all non-cosmopolitan medico-religious disciplines), and on the other hand the improvisation and bricolage by individual healers, all struggling to catch the attention of their potential clients, in order to carve out a place for themselves in this lucrative but competitive market of prestige, power and financial gain.

The four-tablet system is a form of medical technology. It is a material precipitation of medical knowledge and as such seduces 
both therapist and patient to look at reality in a specific and controlled way; it determines specific medical action to a large extent; and has great influence on social relations within the medical practice. ${ }^{22}$ Tracing the history and the contemporary spread helps to explain the present form of the four-tablet system as an example of medical technology, as well as its distribution all over Southern Africa. Its effect on the therapeutic situation largely derives from the same factors which I have claimed are responsible for its relative success (as compared to alternative forms of divination available in the region) under conditions of the modern bureaucratic state and the capitalist economy. Medical technology (in this case an oracular apparatus in combination with its interpretative catalogue) is not only constructed on the basis of a theory of how the world and the human body are constructed-it also imposes that theory on the contact between therapist and client in any situation in which the apparatus is being applied, and from such contacts influences the client's outlook in non-therapeutic social situations.

Here the four-tablet system displays a most significant dialectic. In terms of its contents the interpretative catalogue often relies on notions of ancestors and sorcery. Such aetiological explanations are absent in the dominant, publicly mediated discourse of the state and capitalism concerning the structure of the world; their invocation in the divination context helps to maintain, unobtrusively and often underground, a collective African domain of meaning and choice which ignores dominant power relations (the hegemony of the political and economic centre), or at least puts them in a relative light and suggests alternatives to them (van Binsbergen 1993a). In formal terms however the properties of the four-tablet divination apparatus (standardisation, commoditification, impersonal classification according to an interpretative catalogue lacking microdramatics) are remarkably well in line with the structure of the social experience under the state and capitalism, and via an apparent detour of 'traditional' medicine these formal characteristics reinforce the systematics and the subjective inescapability of the modern political and economic order. The four-tablet oracle expresses not only a non-cosmopolitan medico-religious sub-system in the periphery of the Southern African society, but also the fundamental orientations and power relationships of that society as a whole, and is partly legitimated by this congruence (which is further confirmed by the alliances between state and diviners within the latter's professional organisations). 
Viewed in this light the four-tablet oracle is far less exotic, and has much more in common with the cosmopolitan doctor's blood pressure gauge and stethoscope, than we would suspect at first view. It constitutes another example, from an unexpected (for noncosmopolitan) angle, of how in the modern world globalizationincluding the construction and salvaging of identity-seeks to break through via material objects which have become commodities (Appadurai 1986; van Binsbergen 1992).

\section{NOTES}

1. Earlier versions of this paper were presented at the '8e Marktdag Medische Sociologie/Antropologie', Amsterdam, November 1990; Annual Conference, Association of Anthropologists of Southern Africa, Durban-Westville, September 1992; the conference on 'Symbols of change: Trans-regional culture and local practice in Southern Africa', Berlin, 7-10 January, 1993; and the African Studies Centre seminar, 12th January 1993. I am indebted to many colleagues present on those occasions for constructive criticism, particularly to Sjaak van der Geest, Gina Buijs, Ed Wilmsen, Jim Denbow, Ute Luig and Elizabeth Colson; further to Louis Brenner, Aron Mazel, Adrian Hastings and the Librarian in charge of Oriental manuscripts at Leiden University. Without the untiring enthusiasm of the library staff at the African Studies Centre and the generous financial support from that institution's Board this study would not have been possible.

2. For fuller ethnographic detail cf. van Binsbergen, 1994, forthcoming, and in prep.

3. Junod 1927: ii, 539f; Bourdillon 1976: 177f; Gelfand 1964: 77f; Gelfand 1956: 116, 148f; Reynolds 1963: 104. This type of oracle also occurs in West Africa: Trautmann 1939: 25 (illustration), 92f.

4. This does not always involve sixteen combinations, each with a $0.06(=1 / 16)$ probability. Among the Tswana and the northern Sotho of Botswana and South Africa (groups which are closely related; cf. Campbell 1968; de Jager \& Seboni 1964; Werbner 1989b; Eiselen 1932) a special form of the four-tablet system as described here is being used. Here both male tablets are pyramidally-shaped parts of cattle hoofs, which may fall on either of four sides; the female tablets however are the usual flat tablets with one marked and one unmarked side, as known from Francistown. In such a case the formula for the number of configurations is: $\mathrm{C}=\left(\mathrm{n}_{\mathrm{a}}\right)^{\mathrm{k}_{\mathrm{a}}}\left(\mathrm{n}_{\mathrm{b}}\right)^{\mathrm{k}_{\mathrm{b}}}$, where $\mathrm{n}_{\mathrm{a}}=$ number of different values which an element of type a (either tablet, or hoof) can assume, $k_{a}=$ number of different elements of type $\mathrm{a}$, and likewise mutatis mutandis for $\mathrm{n}_{\mathrm{b}}$ and $\mathrm{k}_{\mathrm{b}}$; in this specific case: $\mathrm{C}=4^{2} * 2^{2}=64$. This number is actually mentioned by Eiselen (who gives the praise, and the interpretation implied therein, for each configuration), Campbell, and Staugård.

5. Bascom 1969, 1980; Trautmann 1939; Monteil 1931; Maupoil 1943; Hébert 1961; Jaulin 1966; Adler \& Zempléni 1972; and extensive bibliographical references there.

6. Stigand 1966 (East Africa); Trautmann 1939; Hébert 1961; Jaulin 1966; Vérin \& Narivelo Rajaonarimanana 1991; and extensive bibliographical references there.

7. Fahd 1966, 1978; Maupoil 1943; Jaulin 1966; Hébert 1961. 
8. Cf Loewe \& Blacker 1981 and extensive bibliographical references there; on I Ching see also Wilhelm 1973, and there Jung's (1973) foreword.

9. Bent 1892; Berglund 1989; Bleek 1928; Bourdillon 1976; Buijs 1992; Campbell 1968; Coertze 1931; de Jager \& Seboni 1964; Dornan 1923; Eiselen 1932; Frobenius 1931; Garbutt 1909; Giesekke 1930; Hunt 1950, 1954, 1962; Junod 1927; Laydevant 1933; Nettleton 1984; Reynolds 1963, 1968; Roberts 1915; Stayt 1931; Tracey 1963; von Sicard 1959; Watt \& van Warmerlo 1930; Werbner 1989; Willoughby n.d.

10. On bureaucratizing professionalization of autochthonous medicine within national professional organisations, also in Southern Africa, cf. Last \& Chavunduka 1986; Dennis 1978: 60; Chavunduka 1978. The author has been a certified member of the Kwame (/Legwame) Traditional Association of medical practitioners in Botswana since 1990 (van Binsbergen 1991).

11. The final $-e$ in both names tends to be pronounced as the Italian $i$.

12. Whom the Tswana call Nape; Brown 1926: 112. Against the background of the extensive Arabian connection of the four-tablet system as argued elsewhere (van Binsbergen forthcoming and in prep.), I suggest an etymological link with the Semitic nabi, 'prophet'.

13. As Schoffeleers (1991) has recently argued, the same strategy of acquiescence is applied in the symbolic, moral and political stance of, particularly, South African healing churches; outside South Africa, however, his thesis cannot be generalised for the whole of Southern Africa, cf. van Binsbergen 1993b.

14. The urban-rural distinction and phase difference, although only gradual in contemporary Southern Africa, largely explains the apparent contradiction between the conventionalised Francistown system as described by me, and the microdramatic, praise-centered system as described by Werbner (1989) for a Tswana rural setting in post-independence Botswana.

15. E.g. Gelfand 1956: 103, 1964: 79; Hunt 1950: 45.

16. Berglund 1989: 194 n. 64; Reynolds 1963: 108.

17. Reynolds 1963: 108; Nettleton 1984: i, 309f.

18. Gieseke 1930-31: 266; Nettleton 1984: i, 328; my own field-work.

19. Schapera 1984: 256, n. 1; Berglund 1989: 194 n. 64.

20. For Botswana: cf. Campbell 1979: 56; Dennis 1978: 59-61; Schapera 1984a: 255; the Witchcraft Proclamation of 1927 in Staugård 1986: 86; for Zimbabwe: Howman 1949; Howmann 1918: 389, Reynolds 1963: 105 and Tracey 1934a: 23 (confiscation of tablets), moreover Hunt 1950 (diviners' fear to admit their knowledge of sorcery before a colonial civil servant), and Chavunduka 1978: 101f (legislation); for Zambia: Reynolds 1963: 166f (legislation).

21. Cf. Frobenius 1931: see his index under Ritualmord; Wilson 1931.

22. Cf. van der Geest 1990; Bronzino et al. 1990.

\section{BIBLIOGRAPHY}

Adler, A., \& Zempléni, A.

1972 Le Bâton de l'aveugle: Divination, maladie et pouvoir chez les Moundang du Tchad, Paris: Hermann.

Appadurai, A., ed.

1986 The social life of things: commodities in cultural perspective, Cambridge: Cambridge University Press.

Bascom, W.

1969 Ifa divination: Communication between gods and men in West Africa, Bloomington: Indiana University Press. 
1980 Sixteen cowries: Yoruba divination from Africa to the New World, Bloomington: Indiana University Press.

Bent, J.T.

1892 The ruined cities of Mahonaland, London: Longmans, Green \& Co.

Berglund, A.-I.

1989 Zulu thought-patterns and symbolism, London/Cape Town \& Johannesburg: Hurst/David Philip, reprint of first edition of 1976.

Bleek, D.F.

1928 The Naron: A Bushman tribe of the Central Kalahari, Cambridge.

Bourdillon, M.

1976 The Shona peoples: An ethnography of the contemporary Shona, with special reference to their religion, Gwelo: Mambo Press.

Bronzino, J.D., V.H. Smith \& M.L. Wade,

1990 Medical technology and society: An interdisciplinary perspective, Cambridge

Brown, J.T. (Mass.): Massachusetts Institute of Technology Press.

1926 Among the Bantu Nomads: A record of forty years spent among the Bechuana a numerous \& famous branch of the Central South African Bantu, with the first full description of their ancient customs, manners \& beliefs, London: Seeley, Service \& Co Ltd.

Buijs, G.

1992 'Sources of power: The role of the divining dice (thangu) in Venda cosmology', paper read at the Anthropology Association of Southern Africa Annual Meeting, Durban-Westville, September 1992.

Campbell, A.C.

1968 'Some notes on Ngwaketse divination', Botswana Notes and Records, 1:913; reprinted as Campbell 1979.

1979 'Some notes on Ngwaketse divination', in: Z.A. Ademuwagun, J.A.A. Ayoade, I.E. Harrison \& D.M. Warren (eds.), African therapeutic systems, Waltham (Mass.): African Studies Association, Crossroads Press, pp. 56-57.

Chavunduka, G.L.

1978 Traditional healers and the Shona patient, Gwelo: Mambo Press.

1986 'The organisation of traditional medicine in Zimbabwe', in: Last \& Chavunduka 1986: 29-50.

Coertze, P.J.

1931 Dolosgooiery in Suid-Afrika, Stellenbosch: University of Stellenbosch, Annale van die Universiteit. van Stellenbosch, vol. ix, series B, issue 2.

Crowley, E.

1989 The Zulu bone oracle: Devised and with commentary by Ulufudu, Berkeley: Wingbow Press.

de Jager, E.J., \& O.M. Seboni

1964 'Bone divination among the Kwena of Molepolole district,

Devisch, R. Bechuanaland Protectorate', Afrika und Übersee, 48: 2-16.

1985 'Perspectives on divination in contemporary sub-Saharan Africa', in: van Binsbergen, W.M.J. \& Schoffeleers, J.M., (eds.), Theoretical explorations in African religion, London/Boston: Kegan Paul International, pp. 50-83.

1991 'Mediumistic divination among the northern Yaka of Zaire', in: Peek 1991 a: 112-132.

Dornan, S.S.

1923 'Divination and divining bones', South African Journal of Science, 20: 504-511. 
Eiselen, W.

1932 'The art of divination as practised by the Bamasemola', Bantu Studies, 6: 1-29, 251-263.

Fahd, T.

1966 La divination arabe: Etudes religieuses sociologiques et folkloriques sur le milieu natif de l'Islam, Leiden: Brill.

1978 'Khatț', in: C.E. Bosworth, E. van Donzel, B. Lewis \& C. Pellat, eds., The Encyclopaedia of Islam, new edition, volume IV, fasc. 77-78, Leiden: Brill, pp. 1128-1130.

Frobenius, L.

1931 Erythräa: Länder und Zeiten des heiligen Königsmordes, Berlin/Zürich: Atlantis-Verlag.

Garbutt, H.W.

1909 'Native witchcraft and superstition in South Africa', Proceedings of the Rhodesia Scientific Association, 9: 40-80

Gelfand, M.

1956 Medicine and magic of the Mashona, Johannesburg: Jutta.

1964 Witch doctor: Traditional medicine man of Rhodesia, London: Harvill Press.

Giesekke, E.D.

1930 'Wahrsagerie bei den baVenda', Zeitschrift für Eingeborensprache, 21, 1: 257-310.

Hammond-Tooke, W.D.

1974 'World-View II: A system of action', in: W.D. Hammond-Tooke, ed., The Bantu-speaking peoples of Southern Africa, London: Routledge \& Kegan Paul, pp. 344-363.

Hammond-Tooke, W.D.

1981 Boundaries and belief: The structure of a Sotho worldview, Johannesburg: Witwatersrand University Press, Human Sciences Reaearch Council Publication Series No. 74.

Howman, R.

1949 'Witchcraft and the law', Native Affairs Department Annual (NADA), 25: 7-18.

Howmann, E.G.

1918 'The traditional history and customs of the Makaranga', South African Journal of Science, 15: 383-393.

Hunt, N.

1950 'Some notes on witchdoctor's bones', Native Affairs Department Annual (NADA), 27: 40-46.

1954 'Some notes on witchdoctor's bones', Native Affairs Department Annual (NADA), 31: 16-23.

1962 'More notes on witchdoctor's bones', Native Affairs Department Annual (NADA), 39: 14-16.

Jaulin, R.

1966 La géomancie: Analyse formelle, Cahiers de l'Homme, EthnologieGéographie-Linguistique, N.S., iv, Paris: Mouton.

Jung, C.G.

1973 'Voorwoord', in: Wilhelm, R., translator, I Tjing: Het boek der veranderingen, Deventer: Ankh-Hermes, fifth impr. (first impr., Amsterdam: L.J. Veen 1953), pp. xvi-xxxiii.

Junod, H.A.

1925 'La divination au moyen de tablettes d'ivoire chez les Pedis', Bulletin de la Société de Neuchâtel de Géographie, 34: 38-56.

1927 The life of a South African tribe, London: Macmillan. 
Last, M. \& G.L. Chavunduka, eds.

1986 The professionalisation of African medicine, Manchester: Manchester University Press and International African Institute.

Laydevant, F.

1933 'The praises of the divining bones among the Basutho', Bantu Studies, 7: 341-373.

Lee, S.G.

1969 'Spirit possession among the Zulu', in: J. Beattie \& J. Middleton, eds., Spirit mediumship and society in Africa, London: Routledge \& Kegan Paul,

Lipschutz, S. pp. 128-156.

1983 Theory and problems of finite mathematics: SI (metric) edition, New York etc.: McGraw-Hill, Schaum's Outline Series, 4e druk.

Loewe, M. \& C. Blacker, eds.

1981 Oracles and divination, London etc.: Allen \& Unwin.

Maupoil, B.

1943 'Contribution à l'origine musulmane de la géomancie dans le Bas-

Monteil, C. Dahomey', Journal de la Société des Africanistes, 13.

1931 'La divination chez les Noirs de l'O.A.F. [Afrique Occidentale française]', Bulletin du Comité d'études historiques et scientifiques de l'Afrique Occidentale Française, xiv (1/2): 72-136.

Nettleton, A.C.E.

1984 'The traditional figurative woodcarving of the Shona and Venda', 2

Peek, P.M. vols, Ph.D. thesis, University of Witwatersrand.

1991a ed., African divination systems: Ways of knowing, Bloomington: Indiana University Press.

$1991 \mathrm{~b}$ 'African divination system: Non-normal modes of cognition', in: Peek 1991a: 193-212.

Reynolds, B.

1963 Magic divination and witchcraft among the Barotse of Northern Rhodesia, Berkeley \& Los Angeles: University of California Press.

1968 The material culture of the peoples of the Gwembe valley, Manchester: Manchester University Press.

Roberts, N.

1915 "A few notes on "To Kolo", a system of divination practised by the superior native of Malaboch's Tribe in Northern Transvaal', South African Journal of Science, 11: 367-370.

Robinson, K.R.

1959 Khami ruins, Cambridge: Cambridge University Press.

Schapera, I.

1984a A handbook of Tswana law and custom, London: Cass; new impression of the second edition of 1955 (first was 1938).

Schoffeleers, J.M.

1991 'Ritual healing and political acquiescence: The case of Zionist churches in Southern Africa', Africa, 61, 1: 1-25.

Shaw, R.

1991 'Splitting truths from darkness: Epistemological aspects of Temne divination', in: Peek 1991a: 137-152.

Stayt, $\mathrm{H}$.

1931 The Bavenda, London: Oxford University Press. 
Stigand, G.H.

1966 The land of Zinj: Being an account of British East Africa, its ancient history and present inhabitants, London: Frank Cass, new impression of the 1913 first edition.

Tracey, $\mathrm{H}$.

1963 'The hakata of Southern Rhodesia', Native Affairs Department Annual (NADA), 40: 105-107.

Trautmann, R.

1939/1940 La divination à la Côte des Esclaves et à Madagascar: Le Vôdoû Fa-le Sikidy, Mémoires de l'Institut Français d'Afrique Noire, no. 1, Paris: Larose. [according to cover 1939, according to title page 1940].

van Binsbergen, W.M.J.

1991 'Becoming a sangoma: Religious anthropological fieldwork in Francistown, Botswana', Journal of Religion in Africa, 21, 4: 309-344.

1992 Kazanga: Etniciteit in Afrika tussen staat en traditie, inaugural lecture, Amsterdam: Vrije Universiteit; French version: 'Kazanga: Ethnicité en Afrique entre Etat et tradition'. in: W.M.J. van Binsbergen \& K. Schilder, eds., Perspectives on Ethnicity in Africa, special issue on ethnicity, Afrika Focus, Gendt (Belgium), 1993, 1: 9-40; English version in press in African Studies, 1994.

1993a 'Making sense of urban space in Francistown, Botswana', in: P.J.M. Nas, ed., Urban symbolism, Leiden: Brill, Studies in Human Societies volume 8, 1993, pp. 184-228.

$1993 \mathrm{~b}$ 'African Independent churches and the state in Botswana', in M. Bax \& A. de Koster, eds., Power and prayer: Essays on Religion and politics, CentREPOL-VU Studies 2, Amsterdam: VU University Press, pp. 24-56.

1994 'Divinatie met vier tabletten: Medische technologie in Zuidelijk Afrika', in: S. van der Geest, P. ten Have, G. Nijhoff en P. VerbeekHeida, eds., De macht der dingen: Medische technologie in cultureel perspectief, Amsterdam: Spinhuis, pp. 61-110.

forthcoming, 'Regional and historical connections of four-tablet divination in Southern Africa', Journal of Religion in Africa, 1996.

in prep., Four tablets: A Southern African divination system in its transregional and historical context.

van der Geest, J.D.M.

1990 'De sociale en culturele betekenis van medische technologie', Anthropologische Verkenningen, 9, 2: 49-56.

Vérin, P. \& Narivelo Rajaonarimanana

1991 'Divination in Madagascar: The Antemoro case and the diffusion of divination', in: Peek 1991a: 53-68.

von Sicard, $\mathrm{H}$.

1959 'The hakata names', Native Affairs Department Annual (NADA), 36: 26-29.

Watt, J.M. \& N.F. van Warmelo

1930 'The medicines and practice of a Sotho doctor', Bantu Studies, 4: 47-63.

Werbner, R.P.

1989a Ritual passage sacred journey: The process and organization of religious movement, Washington/Manchester: Smithsonian Institution Press/Manchester University Press.

1989b 'Making the hidden seen: Tswapong wisdom divination', in: Werbner 1989a: 19-60.

\section{Copyright (c) 2004 ProQuest Information and Learning Company


Wilhelm, R., (translator)

1973 I Tjing: Het boek der veranderingen, Deventer: Ankh-Hermes, 5th impr. (1st impr. Amsterdam: L.J. Veen 1953), pp. xvi-xxiii.

Willoughby, W.C.

n.d., [probably based on Willoughby's journey to Tati in 1913], 'Dice', no. WCW/SO 790, 1 typed page, in: 'Notes on Kalanga history, religion and customs (in English, Setswana and Ikalanga) extracted from the papers of Prof. W.C. Willoughby', Selly Oak Colleges Library, Birmingham; photocopy graciously made available by Wilson, A. Dr. Q.N. Parsons.

1931 'The Human sacrifice', NADA (Native Affairs Department Annual), 9: 6-10. 